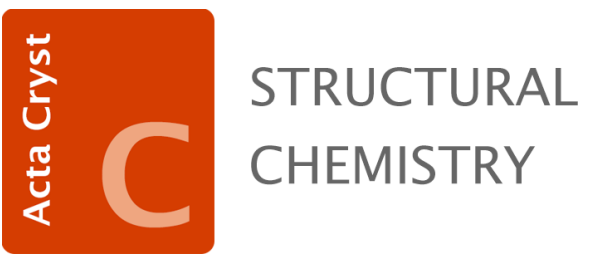

Volume 77 (2021)

Supporting information for article:

New solvates and a salt of the anti-HIV compound etravirine Marieta Muresan-Pop, Sergiu Macavei, Alexandru Turza and Gheorghe Borodi 
Hirshfeld surfaces and Fingerprint plots: The 2D fingerprint plots of studied solid forms highlighting the close intercontacts are illustrated in Figure 7a, b, c, d, e. Each etravirine and each solvent molecule of the studied crystals were treated separately.
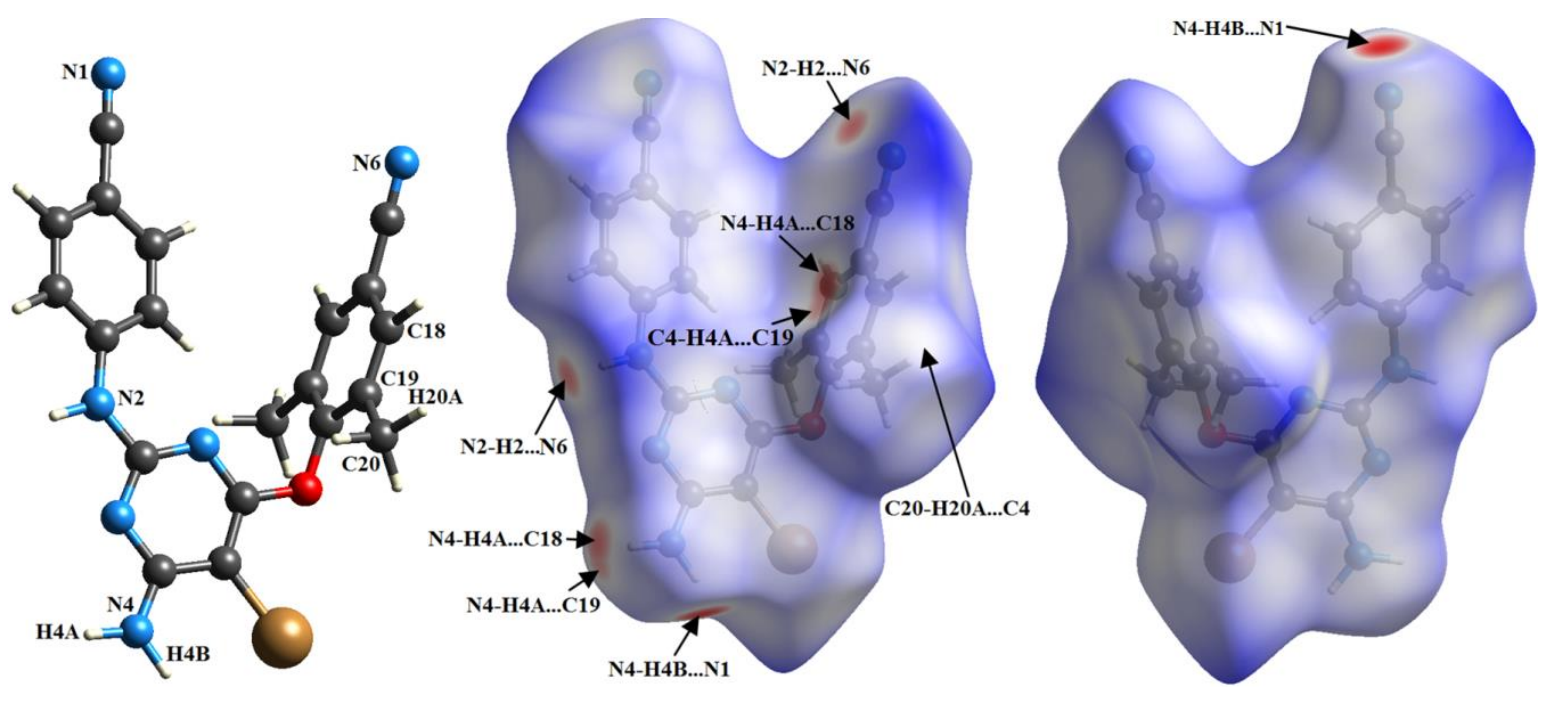

(a)

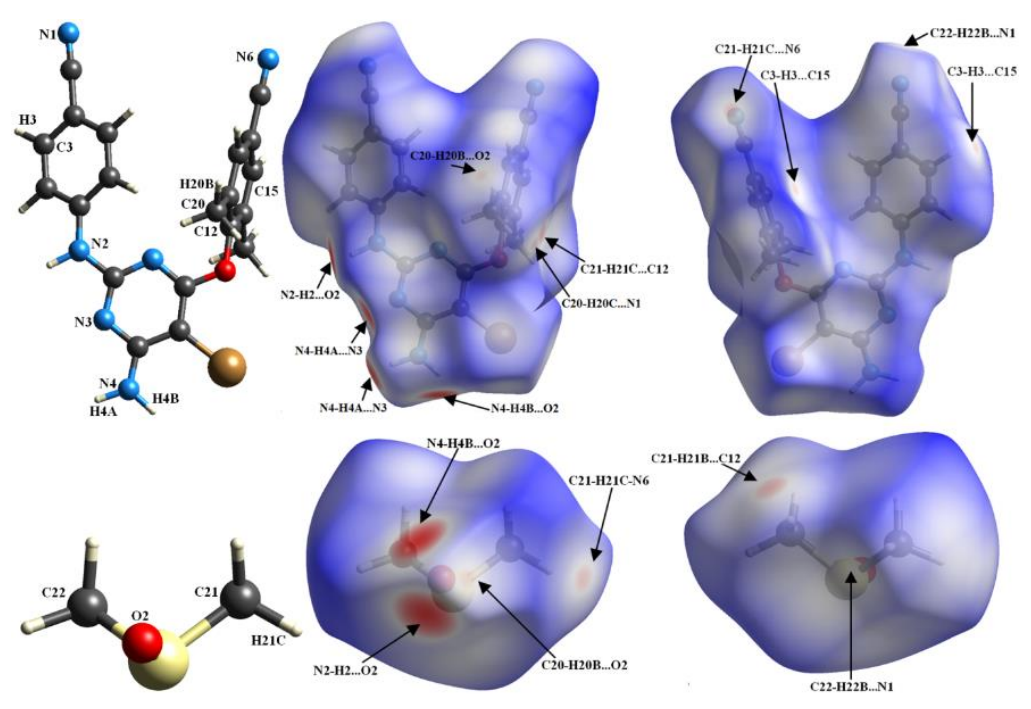

(b) 

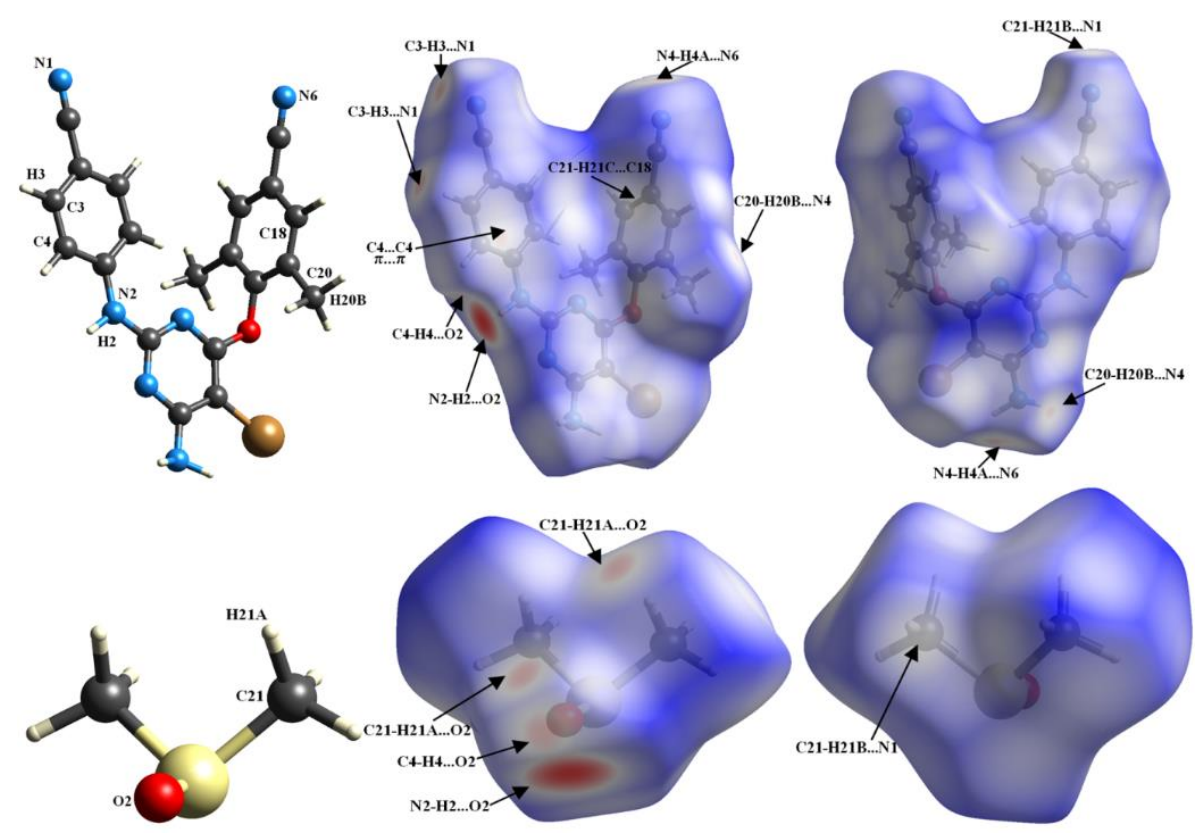

(c)

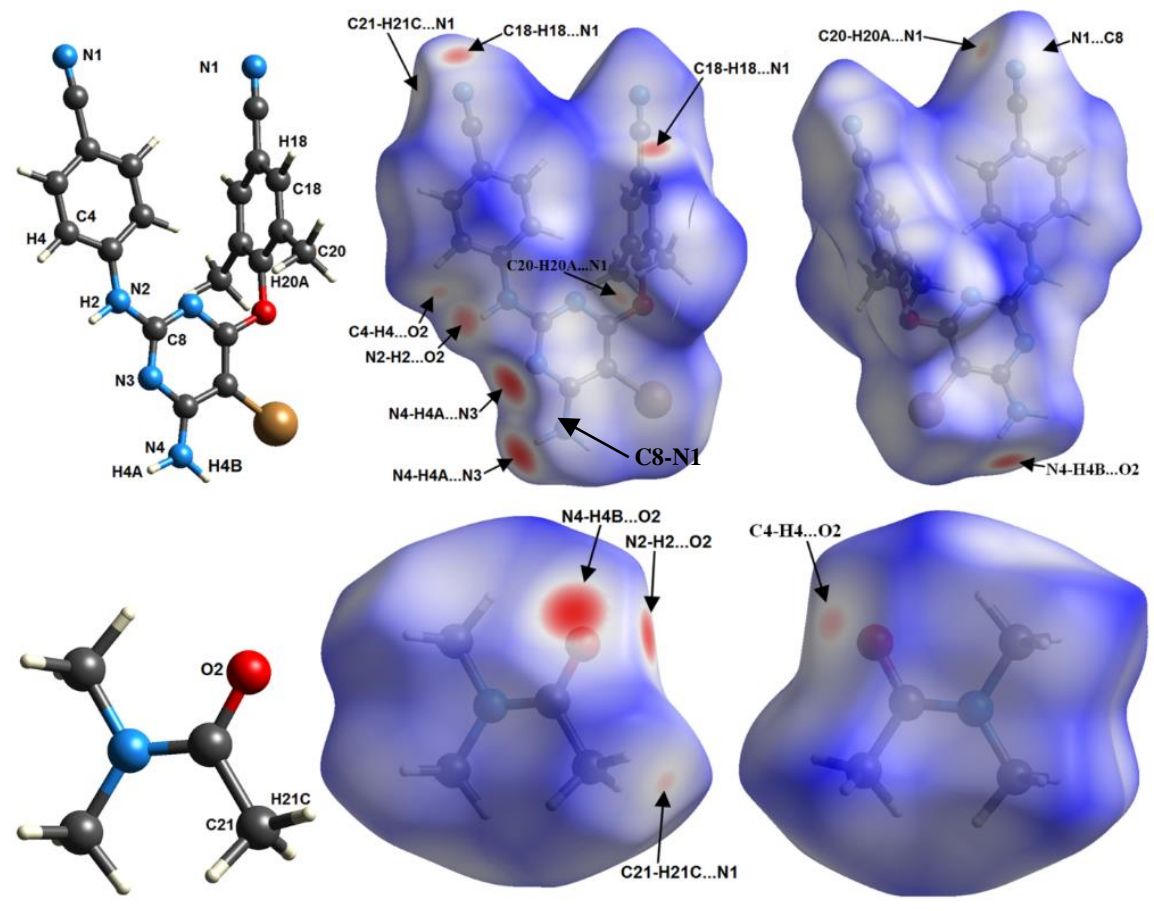

(d) 


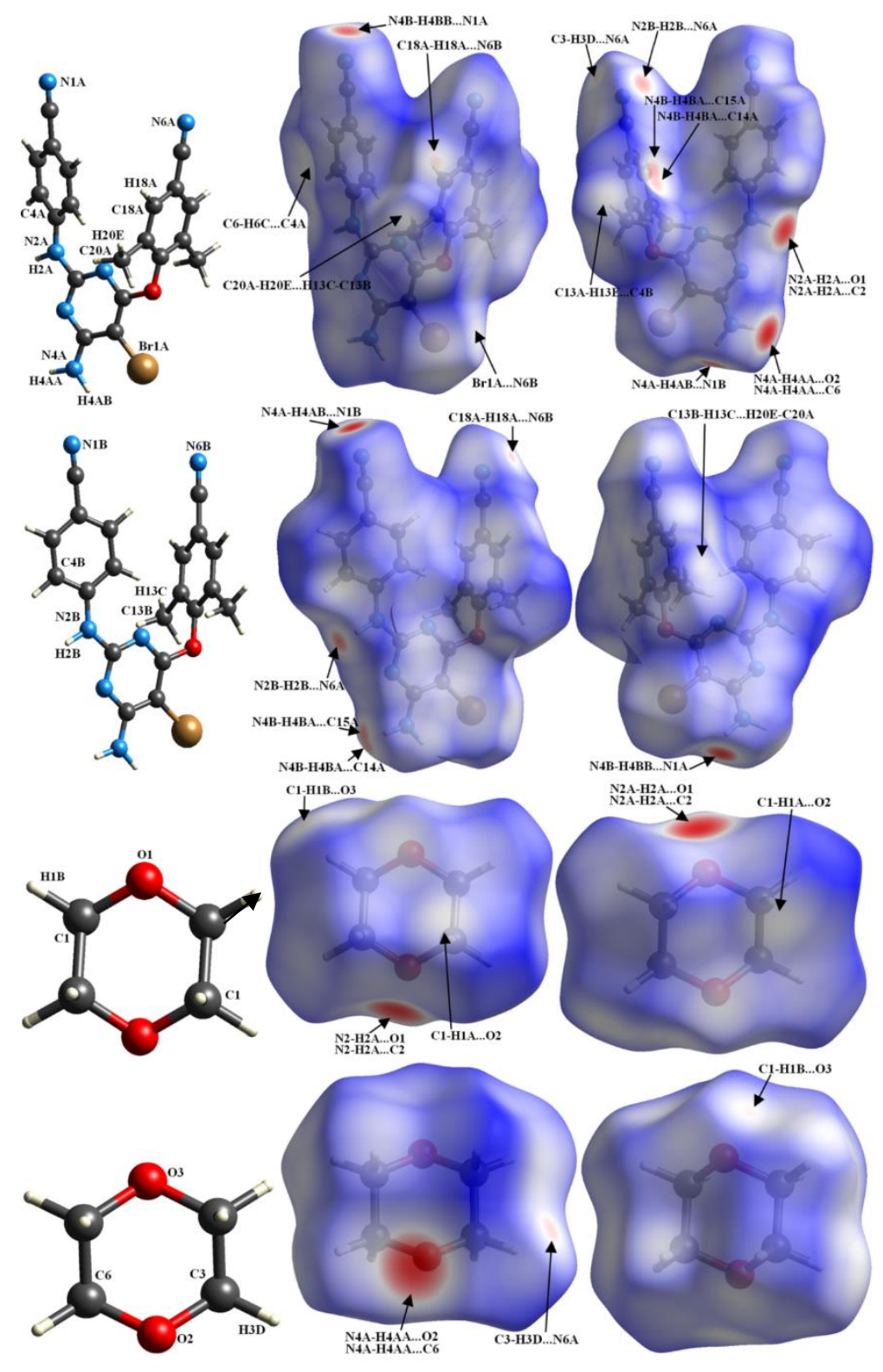

(e)
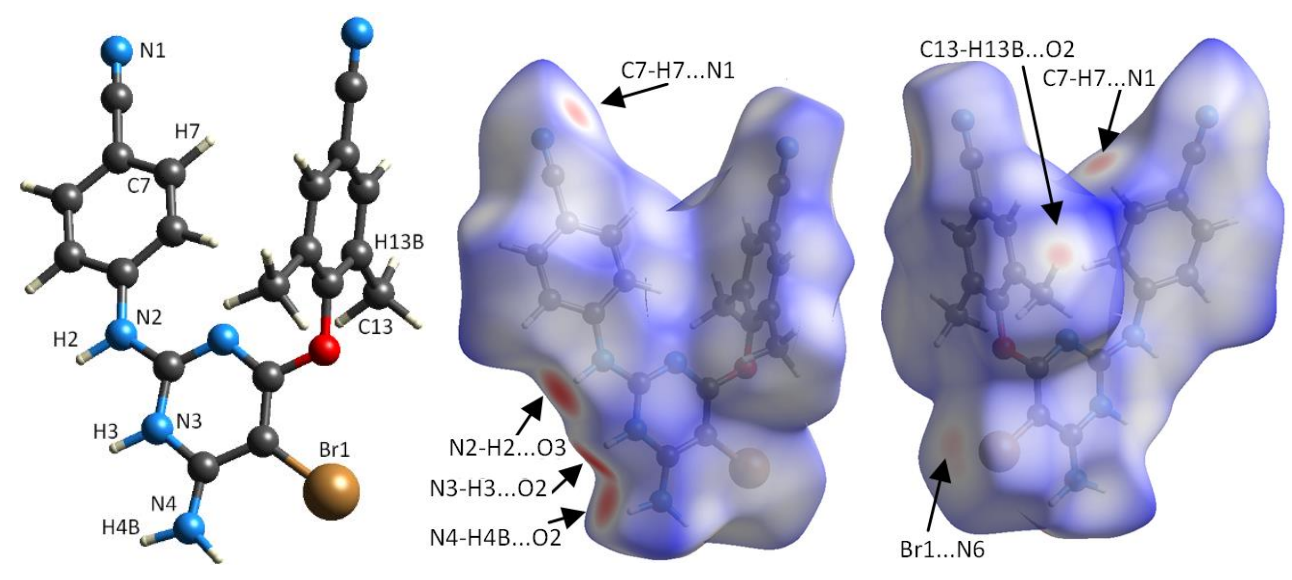

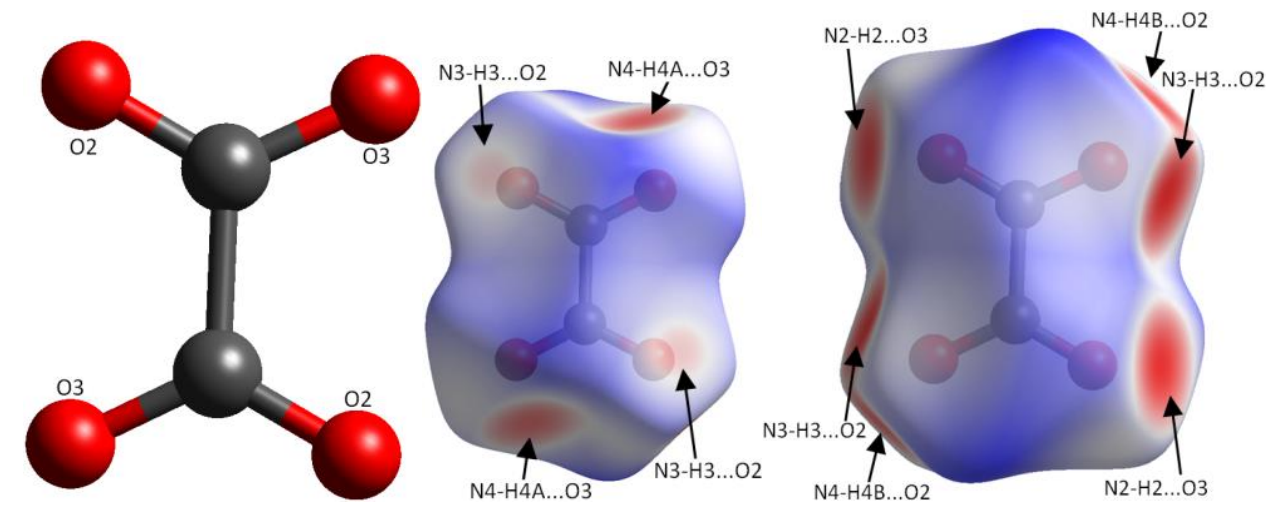

(f)

Figure 7. Perspective views of the Hirshfeld surfaces mapped with $d_{\text {norm }}$ highlighting the intermolecular contacts referred in Table 2: ETR (a), ETR-DMSO1 (b), ETR-DMSO2 (c), ETR-DMA (d), ETRDioxane (e) and ETR-Oxalic (f). The surfaces were represented with the clour scale in the ranges as follows: -0.36 (red) to 1.77 (blue) for ETR, -0.50 (red) to 1.54 (blue) for ETR-DMSO1, -0.54 (red) to 1.54 (blue) for ETR-DMSO2, -0.43 (red) to 1.50 (blue) for ETR-DMA, -0.52 (red) to 1.37 (blue) for ETR-Dioxane; -0.72 (red) to 1.75 (blue) for ETR-Oxalic.

Table S1. Classical hydrogen bonds (highlighted as bold text) and intermolecular contacts with distances shorter than the sum of van der Waals radii $\left(\AA,{ }^{\circ}\right)$

\begin{tabular}{|c|c|c|c|c|c|c|c|}
\hline Structure & D-H $\cdots \mathbf{A}$ & d(D-H) & $\mathbf{d}(\mathbf{H} \ldots \mathbf{. . A})$ & $\mathbf{d}(\mathbf{D} \ldots \mathbf{. . A})$ & $<$ (DHA) & Spot type & Fig. 7 \\
\hline \multirow[t]{7}{*}{ ETR } & $\mathrm{N} 2-\mathrm{H} 2 \cdots \mathrm{N} 6$ & 0.86 & $2.514(5)$ & 3.373(5) & $175.85(12)$ & Red & \multirow{7}{*}{$\mathbf{a}$} \\
\hline & N4-H4A $\cdots \mathrm{C} 18$ & 0.86 & $2.615(4)$ & $3.460(4)$ & 167.33(10) & Red & \\
\hline & N4-H4A…C19 & 0.86 & $2.739(5)$ & $3.555(5)$ & $158.87(11)$ & Red & \\
\hline & N4-H4B $\cdots$ N1 & 0.86 & $2.289(5)$ & 3.087(5) & $154.23(12)$ & Deep red & \\
\hline & C20-H20A ‥C4 & 0.96 & $2.864(3)$ & $3.632(6)$ & 138.01(3) & White & \\
\hline & N4A-H4A $\cdots$ C18 & 0.86 & $2.615(4)$ & $3.460(8)$ & 167.33(10) & Red & \\
\hline & N4A-H4A $\cdots$ C19 & 0.86 & $2.739(5)$ & $3.555(5)$ & $158.87(11)$ & Red & \\
\hline \multirow[t]{9}{*}{$\begin{array}{l}\text { ETR molecule of } \\
\text { ETR-DMSO1 }\end{array}$} & $\mathrm{N} 2-\mathrm{H} 2 \cdots \mathrm{O} 2$ & 0.86 & $2.094(4)$ & $\begin{array}{l}2.933 \\
(2)\end{array}$ & $168.89(6)$ & Deep red & \multirow{9}{*}{ b } \\
\hline & $\mathrm{N} 4-\mathrm{H} 4 \mathrm{~A} \cdots \mathrm{N3}$ & 0.86 & $2.251(1)$ & 3.094(4) & 166.697(4) & Deep red & \\
\hline & N4-H4B $\cdots O 2$ & 0.86 & $2.107(2)$ & $2.798(6)$ & 136.04(4) & Deep red & \\
\hline & $\mathrm{C} 20-\mathrm{H} 20 \mathrm{~B} \cdots \mathrm{O} 2$ & 0.96 & $2.630(4)$ & 3.470(9) & 146.392(3) & Faint red & \\
\hline & C20-H20C $\cdots \mathrm{N} 1$ & 0.96 & 2.656(3) & 3.564(3) & 157.931(7) & Faint red & \\
\hline & C21-H21B ‥C12 & 0.96 & $2.688(3)$ & $3.405(7)$ & $131.950(4)$ & Faint red & \\
\hline & C21-H21C…N6 & 0.96 & $2.636(4)$ & $3.512(6)$ & 151.927(9) & Faint red & \\
\hline & C3-H3…C15 & 0.93 & $2.830(4)$ & 3.734(3) & $164.322(5)$ & Faint red & \\
\hline & C22-H22B $\cdots \mathrm{N} 1$ & 0.96 & $2.685(1)$ & $3.399(6)$ & 131.640(1) & White & \\
\hline \multirow{3}{*}{$\begin{array}{l}\text { DMSO molecule } \\
\text { of ETR-DMSO1 }\end{array}$} & N4-H4B $\cdots O 2$ & 0.86 & $2.107(2)$ & $2.798(6)$ & $137.044(3)$ & Deep red & \\
\hline & 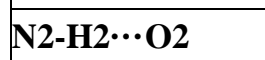 & 0.86 & $2.094(4)$ & $2.933(2)$ & $164.896(9)$ & Deep red & \\
\hline & 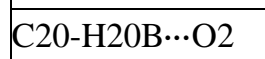 & 0.96 & $2.630(4)$ & $3.470(9)$ & 146.392(3) & Faint red & \\
\hline
\end{tabular}




\begin{tabular}{|c|c|c|c|c|c|c|c|}
\hline Structure & D-H $\cdots A$ & d(D-H) & d(H...A) & d(D...A) & $<$ (DHA) & Spot type & Fig. 7 \\
\hline & C21-H21C...N6 & 0.96 & $2.636(4)$ & $3.512(6)$ & 151.927(9) & Faint red & $\mathbf{b}$ \\
\hline & C21-H21B …C12 & 0.96 & $2.688(3)$ & $3.405(7)$ & $131.950(4)$ & Faint red & \\
\hline & $\mathrm{C} 22-\mathrm{H} 22 \mathrm{~B} \cdots \mathrm{N} 1$ & 0.96 & $2.685(1)$ & $3.399(6)$ & 131.640(1) & White & \\
\hline \multirow{8}{*}{$\begin{array}{l}\text { ETR molecule of } \\
\text { ETR-DMSO2 }\end{array}$} & C3-H3 ‥N1 & 0.93 & $2.586(7)$ & $3.504(3)$ & 169.062(9) & Red & \multirow{8}{*}{ c } \\
\hline & $\mathrm{C} 4-\mathrm{H} 4 \cdots \mathrm{O} 2$ & 0.93 & $2.554(6)$ & $3.321(7)$ & $140.047(4)$ & Faint red & \\
\hline & $\mathrm{N} 2-\mathrm{H} 2 \cdots \mathrm{O} 2$ & 0.86 & $2.052(6)$ & $2.900(8)$ & 168.644(7) & Deep red & \\
\hline & N4-H4A $\cdots$ N6 & 0.861 & $2.538(8)$ & 3.016(7) & $115.966(5)$ & Faint red & \\
\hline & C21-H21C $\cdots \mathrm{C} 18$ & 0.96 & $2.824(9)$ & $3.597(9)$ & 138.198(4) & White & \\
\hline & C20-H20B $\cdots \mathrm{N} 4$ & 0.96 & $2.807(5)$ & $3.735(2)$ & $175.35(3)$ & Faint red & \\
\hline & $\mathrm{C} 4 \cdots \mathrm{C} 4(\pi \cdots \pi)$ & & & $3.332(9)$ & & White & \\
\hline & 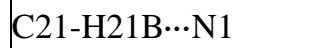 & 0.96 & $2.720(3)$ & $3.585(7)$ & $1.349(7)$ & White & \\
\hline \multirow{4}{*}{$\begin{array}{l}\text { DMSO molecule } \\
\text { of ETR-DMSO2 }\end{array}$} & C21-H21A $\cdots \mathrm{O} 2$ & 0.96 & $2.557(8)$ & $3.493(3)$ & 164.789(4) & Red & \multirow{4}{*}{ c } \\
\hline & $\mathrm{C} 4-\mathrm{H} 4 \cdots \mathrm{O} 2$ & 0.93 & $2.554(6)$ & $3.321(7)$ & $140.047(4)$ & Red & \\
\hline & $\mathrm{N} 2-\mathrm{H} 2 \cdots \mathrm{O} 2$ & 0.86 & $2.052(6)$ & $2.900(8)$ & 168.644(7) & Deep red & \\
\hline & C21-H21B $\cdots$ N1 & 0.96 & $2.720(3)$ & $3.585(7)$ & $1.349(7)$ & White & \\
\hline \multirow{8}{*}{$\begin{array}{l}\text { ETR molecule of } \\
\text { ETR-DMA }\end{array}$} & $\mathrm{C} 18-\mathrm{H} 18 \cdots \mathrm{N} 1$ & 0.93 & $2.486(5)$ & $3.333(1)$ & 151.414(1) & Red & \multirow{8}{*}{ d } \\
\hline & $\mathrm{C} 21-\mathrm{H} 21 \mathrm{C} \cdots \mathrm{N} 1$ & 0.96 & $2.653(7)$ & $3.460(7)$ & 141.954(3) & Faint red & \\
\hline & $\mathrm{C} 4-\mathrm{H} 4 \cdots \mathrm{O} 2$ & 0.93 & $2.578(8)$ & $3.295(7)$ & $134.236(3)$ & Faint red & \\
\hline & $\mathrm{N} 2-\mathrm{H} 2 \cdots \mathrm{O} 2$ & 0.86 & $2.428(9)$ & $3.178(2)$ & 146.091(3) & Red & \\
\hline & N4-H4A $\cdots$ N3 & 0.86 & $2.218(7)$ & $3.052(9)$ & 163.409(1) & Deep red & \\
\hline & C20-H20A $\cdots$ N1 & 0.86 & $2.615(7)$ & $3.546(7)$ & 163.201(7) & Faint red & \\
\hline & N4-H4B $\cdots O 2$ & 0.86 & $2.284(4)$ & 2.959(4) & $135.456(3)$ & Deep red & \\
\hline & $\mathrm{N} 1 \cdots \mathrm{C} 8$ & & & $3.241(6)$ & & White & \\
\hline \multirow{4}{*}{$\begin{array}{l}\text { DMA molecule } \\
\text { of ETR-DMA }\end{array}$} & N4-H4B $\cdots O 2$ & 0.86 & $2.284(4)$ & $2.959(4)$ & $135.456(3)$ & Deep red & \multirow{4}{*}{ d } \\
\hline & $\mathrm{N} 2-\mathrm{H} 2 \cdots \mathrm{O} 2$ & 0.86 & $2.428(9)$ & $3.178(2)$ & 146.091(3) & Deep red & \\
\hline & C21-H21C $\cdots \mathrm{N} 1$ & 0.96 & $2.653(7)$ & $3.460(7)$ & 141.954(3) & Faint red & \\
\hline & $\mathrm{C} 4-\mathrm{H} 4 \cdots \mathrm{O} 2$ & 0.93 & $2.578(8)$ & $3.295(7)$ & $134.236(3)$ & Faint red & \\
\hline \multirow{11}{*}{$\begin{array}{l}\text { ETR molecule A } \\
\text { of ETR-Dioxane }\end{array}$} & N4B-H4BB $\cdots$ N1A & 0.86 & $2.331(8)$ & 3.114(4) & 151.452(4) & Deep red & \multirow{11}{*}{$\mathbf{e}$} \\
\hline & C6-H6C...C4A & 0.97 & $2.844(5)$ & $3.521(7)$ & 127.640(8) & White & \\
\hline & $\begin{array}{l}\text { C20A-H20E } \cdots \text { H13C- } \\
\text { C13B }\end{array}$ & $\begin{array}{l}0.96 / 0.9 \\
6\end{array}$ & $2.374(9)$ & $3.723(4)$ & $\begin{array}{l}144.540(8) / \\
124.442(3)\end{array}$ & White & \\
\hline & C18-H18A $\cdots$ N6B & 0.93 & $2.683(4)$ & $3.521(8)$ & 150.337(2) & Faint red & \\
\hline & C13A-H13E...C4B & 0.96 & $2.850(1)$ & $3.692(2)$ & $146.95(4)$ & White & \\
\hline & Br1A $\cdots$ N6B & & & $3.392(3)$ & & White & \\
\hline & C3-H3D $\cdots$ N6A & 0.97 & $2.600(7)$ & $3.383(5)$ & 137.903(1) & Faint red & \\
\hline & N2B-H2B $\cdots$ N6A & 0.86 & $2.545(5)$ & $3.392(5)$ & $168.509(3)$ & Red & \\
\hline & N4B-H4BA $\cdots \mathrm{C} 15 \mathrm{~A}$ & 0.86 & $2.715(6)$ & $3.550(6)$ & 164.147(3) & Red & \\
\hline & N4B-H4BA $\cdots \mathrm{C} 14 \mathrm{~A}$ & 0.86 & $2.768(5)$ & $3.601(7)$ & 166.670(1) & Red & \\
\hline & C13A-H13E...C4B & 0.96 & $2.849(3)$ & $3.691(8)$ & 147.023(6) & White & \\
\hline
\end{tabular}




\begin{tabular}{|c|c|c|c|c|c|c|c|}
\hline Structure & D-H $\cdots A$ & d(D-H) & d(H...A) & d(D...A) & $<(\mathbf{D H A})$ & Spot type & Fig. 7 \\
\hline & N2A-H2A $\cdots O 1$ & 0.86 & $2.146(6)$ & $3.00(4)$ & $175.080(2)$ & Deep red & \\
\hline & $\mathrm{N} 2 \mathrm{~A}-\mathrm{H} 2 \mathrm{~A} \cdots \mathrm{C} 2$ & 0.86 & $2.802(5)$ & $3.546(9)$ & $145.802(7)$ & Deep red & \\
\hline & N4A-H4AA $\cdots O 2$ & 0.86 & $2.068(6)$ & $2.905(5)$ & $164.199(4)$ & Deep red & \\
\hline & N4A-H4AA $\cdots$ C6 & 0.86 & $2.773(6)$ & $3.451(2)$ & 136.815(9) & Deep red & \\
\hline & N4A-H4AB $\cdots$ N1B & 0.86 & $2.329(8)$ & $3.115(2)$ & 151.972(2) & Deep red & \\
\hline \multirow{7}{*}{$\begin{array}{l}\text { ETR molecule B } \\
\text { of ETR-Dioxane }\end{array}$} & N4A-H4AB $\cdots$ N1B & 0.86 & $2.329(8)$ & 3.115(2) & 151.972(2) & Deep red & \multirow[t]{7}{*}{$\mathbf{e}$} \\
\hline & N2B-H2B $\cdots$ N6A & 0.86 & $2.545(5)$ & $3.392(5)$ & $168.509(3)$ & Red & \\
\hline & N4B-H4BA $\cdots$ C15A & 0.86 & $2.715(6)$ & $3.550(6)$ & 164.147(3) & Red & \\
\hline & N4B-H4BA $\cdots \mathrm{C} 14 \mathrm{~A}$ & 0.86 & $2.768(5)$ & $3.601(7)$ & 166.670(1) & Red & \\
\hline & C18-H18A $\cdots$ N6B & 0.93 & $2.683(4)$ & $3.521(8)$ & $150.337(2)$ & Faint red & \\
\hline & $\begin{array}{l}\text { C20A-H20E } \cdots \text { H13C- } \\
\text { C13B }\end{array}$ & $\begin{array}{l}0.96 / \\
0.96\end{array}$ & $2.374(9)$ & $3.723(4)$ & $\begin{array}{l}144.540(8) / \\
124.442(3)\end{array}$ & White & \\
\hline & N4B-H4BB $\cdots$ N1A & 0.86 & 2.331(8) & 3.114(4) & $151.452(4)$ & Deep red & \\
\hline \multirow{4}{*}{$\begin{array}{l}\text { O1 dioxane of } \\
\text { ETR-Dioxane }\end{array}$} & N2A-H2A $\cdots O 1$ & 0.86 & $2.146(6)$ & $3.00(4)$ & $175.080(2)$ & Deep red & \multirow[t]{4}{*}{$\mathbf{e}$} \\
\hline & N2A-H2A $\cdots$ C 2 & 0.86 & $2.802(5)$ & $3.546(9)$ & 145.802(7) & Deep red & \\
\hline & C1-H1B $\cdots O 3$ & 0.97 & $2.669(3)$ & $3.602(9)$ & 161.626(1) & White & \\
\hline & $\mathrm{C} 1-\mathrm{H} 1 \mathrm{~A} \cdots \mathrm{O} 2$ & 0.97 & $2.686(7)$ & $3.573(2)$ & 152.157(6) & White & \\
\hline \multirow{4}{*}{$\begin{array}{l}\text { O2-O3 dioxane of } \\
\text { ETR-Dioxane }\end{array}$} & N4A-H4AA $\cdots O 2$ & 0.86 & $2.068(6)$ & $2.905(5)$ & $164.199(4)$ & Deep red & \multirow[t]{4}{*}{$\mathbf{e}$} \\
\hline & N4A-H4AA …C6 & 0.86 & $2.773(6)$ & $3.451(2)$ & 136.815(9) & Deep red & \\
\hline & C3-H3D $\cdots$ N6A & 0.97 & $2.600(7)$ & $3.383(5)$ & 137.903(1) & Faint red & \\
\hline & C1-H1B $\cdots O 3$ & 0.97 & $2.669(3)$ & $3.602(9)$ & 161.626(1) & White & \\
\hline \multirow[t]{6}{*}{ ETR-oxalic } & $\mathrm{N} 2-\mathrm{H} 2 \ldots \mathrm{O} 3$ & 0.85 & $1.90(1)$ & $2.754(6)$ & $177.89(3)$ & Deep red & \multirow[t]{6}{*}{$\mathbf{f}$} \\
\hline & N3-H3 $3 \mathrm{O} 2$ & 0.84 & $1.835(4)$ & $2.623(6)$ & 155.41(2) & Deep red & \\
\hline & N4-H4B $\cdots \mathrm{O} 2$ & 0.84 & $2.099(5)$ & 2.837 & $147.05(3)$ & Deep red & \\
\hline & C7-H7 $\cdots \mathrm{N} 1$ & 0.93 & $2.483(3)$ & $3.405(7)$ & 171.59(3) & Red & \\
\hline & C13-H13B $\cdots \mathrm{O} 2$ & 0.96 & $2.523(2)$ & $3.364(6)$ & $146.36(6)$ & Faint red & \\
\hline & $\mathrm{Br} \cdots \mathrm{N} 6$ & & & $3.261(5)$ & & Faint red & \\
\hline
\end{tabular}

The fingerprint plot of ETR (Figure 8a.) shows two sharp spikes (denoted as $\mathrm{N} \cdots \mathrm{H}$ and $\mathrm{H} \cdots \mathrm{N}$ ) and are representing the $\mathrm{N} \cdots \mathrm{H} / \mathrm{H} \cdots \mathrm{N}$ interactions. Spike $\mathrm{H} \cdots \mathrm{N}$ is related to the $\mathrm{N}-\mathrm{H} \cdots \mathrm{N}$ hydrogen bonds, with the shorter distance $\mathrm{d}_{\mathrm{i}}+\mathrm{d}_{\mathrm{e}} \sim 2.15 \AA$ between the N4-H4B donor situated inside the Hirshfeld surface and the $\mathrm{N} 1$ acceptor of the nitrile group outside the surface; spike $\mathrm{N} \cdots \mathrm{H}$ represents the complementary interaction, with the acceptor being situated inside the surface and the donor outside. The $\mathrm{H} \cdots \mathrm{H}$ spike is extending up to the closest distance $\mathrm{d}_{\mathrm{i}}+\mathrm{d}_{\mathrm{e}} \sim 2.35 \AA$, which correspond to C15-H15 $\cdots \mathrm{H} 13 \mathrm{~B}-\mathrm{C} 13$ inercontact. The $\mathrm{C} \cdots \mathrm{H} / \mathrm{H} \cdots \mathrm{C}$ intercontacts, figured as $\mathrm{H} \cdots \mathrm{C}$ spike is indicating the $\mathrm{N}-\mathrm{H} \cdots \pi$ interaction between the N4-H4A donor situated inside the surface and C18 carbon of the phenyl ring outisde the surface, having the shortest contact $d_{i}+d_{e} \sim 2.47 \AA$, while the $C \cdots H$ spike indicates the same interaction but the donor outside and the acceptor inside. 
The fingerprint plot of etravirine molecule in the ETR-DMSO1 compound shows different features compared with the ETR plot. The $\mathrm{N} \cdots \mathrm{H} / \mathrm{H} \cdots \mathrm{N}$ interactions, seen as two sharp spikes are caused by the $\mathrm{N}-\mathrm{H} \cdots \mathrm{N}$ hydrogen bonds. The $\mathrm{H} \cdots \mathrm{N}$ spike shows the interaction between $\mathrm{N} 4-\mathrm{H} 4 \mathrm{~A}$ primary donor, situated inside the surface and the N3 acceptor of the aromatic pyrimidine ring situated outside the surface, having the shortest interaction extended up to $\mathrm{d}_{\mathrm{i}}+\mathrm{d}_{\mathrm{e}} \sim 2.10 \AA$. The complementary N...H spike is seen in mirror, with the donor outside the surface and the acceptor inside the surface. The $\mathrm{H} \cdots \mathrm{O}$ spike shows a more protruding look and indicates the strong $\mathrm{N} 2-\mathrm{H} 2 \cdots \mathrm{O} 2$ hydrogen bond, with the secondary amide donor inside the surface and the $\mathrm{O} 2$ carboxyl of dimethyl sulfoxide molecule outside the surface, with a distance $\mathrm{d}_{\mathrm{i}}+\mathrm{d}_{\mathrm{e}} \sim 1.95 \AA$. The $\mathrm{H} \cdots \mathrm{H}$ interactions are seen on the fingerprint plot as a very wide spike, with the shortest distance $d_{i}+d_{e} \sim 2.20 \AA$ realized between the primary amies. Both, the $N \cdots H / H \cdots N$ and $\mathrm{H} \ldots \mathrm{O}$ interactions are causing intinse red spots on the Hirshfeld surface and are implied in supramolecular synthons formation (Fig. 8b). The dimethyl sulfoxide fingerprint plot shows the $\mathrm{O} \cdots \mathrm{H}$ interactions caused by the $\mathrm{N} 2-\mathrm{H} 2 \cdots \mathrm{O} 2$ hydrogen bond with the acceptor inside the surface and the $\mathrm{N}-\mathrm{H}$ donor outside, complementary with the fingerprint plot of etravirine molecule.

As expected, because the packing features of ETR-DMSO2 are different compared with ETR-DMSO1, this will result in different overall shape of the fingerprint plots. (Fig. 8c). The spikes caused by $\mathrm{N} \cdots \mathrm{H} / \mathrm{H} \cdots \mathrm{N}$ interactions are less sharp and barely, the $\mathrm{C} 3-\mathrm{H} 3 \cdots \mathrm{N} 1$ interaction having the shortest distance $\mathrm{d}_{\mathrm{i}}+\mathrm{d}_{\mathrm{e}} \sim 2.43 \AA$, with the $\mathrm{C} 3-\mathrm{H} 3$ donor inside the surface and the N1 nitrogen of the nitrile group outside for the $\mathrm{H} \cdots \mathrm{N}$ spike, while the $\mathrm{N} \cdots \mathrm{H}$ is just the opposite. Once again, as in ETR-DMSO1, the $\mathrm{H} \cdots \mathrm{O}$ spike on the fingerprint plot, caused by the $\mathrm{N} 2-\mathrm{H} 2 \cdots \mathrm{O} 2$ hydrogen bond extends up to the distance $\mathrm{d}_{\mathrm{i}}+\mathrm{d}_{\mathrm{e}} \sim 1.90 \AA$, with the secondary amide N2-H2 donor inside and the carboxyl O2 acceptor outside the Hirshfeld surface. The shortest distance for $\mathrm{H} \cdots \mathrm{H}$ interactions, being the $\mathrm{C} 4-\mathrm{H} 4 \cdots \mathrm{H} 21 \mathrm{~A}-\mathrm{C} 21$ interaction $\left(\mathrm{d}_{\mathrm{i}}+\mathrm{d}_{\mathrm{e}} \sim 2.33 \AA\right)$ on the fingerprint plot is slightly higher compared with ETR-DMSO1 but the corresponding $\mathrm{H} \cdots \mathrm{H}$ spike is sharper. The common feature on the fingerprint plot of dimethyl sulfoxide molecule is the $\mathrm{O} \cdots \mathrm{H}$ spike, characteristic to the strong $\mathrm{N}-\mathrm{H} \cdots \mathrm{O}$ hydrogen bonds. By contrast with dimethyl sulfoxide molecule of ETR-DMSO1, which do not show characteristic H $\cdots \mathrm{H}$ spike, in ETRDMSO2 this feature is present, with $\mathrm{d}_{\mathrm{i}}+\mathrm{d}_{\mathrm{e}} \sim 2.33 \AA$, connecting the methyl group of the dimethyl sulfoxide molecule and the phenyl ring in etravirine. The $\mathrm{H} \cdots \mathrm{O}$ spike, being related to the $\mathrm{C} 21$ $\mathrm{H} 21 \mathrm{~A} \ldots \mathrm{O} 2$ interaction between the methyl donor of dimethylacetamide molecule and a neighbour oxygen of the carboxyl acceptor has the $\mathrm{d}_{\mathrm{i}}+\mathrm{d}_{\mathrm{e}} \sim 2.43 \AA$.

The spikes shape in ETR-DMA structure resembles closely the ETR-DMSO1, with the difference that the $\mathrm{H} \cdots \mathrm{O}$ spike is less protruding and is caused by the N4-H4B $\cdots \mathrm{O} 2$ hydrogen bond, which links the nitrogen of the primary amide (inside the surface) and the carboxyl of the dimethylacetamide molecule oxygen (outside the surface), having a $\mathrm{d}_{\mathrm{i}}+\mathrm{d}_{\mathrm{e}} \sim 2.18 \AA$. (Fig. $8 d$ ) The $\mathrm{N} \cdots \mathrm{H} / \mathrm{H} \cdots \mathrm{N}$ intercontacts, with the shortest distance $\mathrm{d}_{\mathrm{i}}+\mathrm{d}_{\mathrm{e}} \sim 2.07 \AA$ are identified on the fingerprint plot as $\mathrm{N} \cdots \mathrm{H}$ spike, having the primary 
amide N4-H4A donor inside the surface and the N3 nitrogen of the pyrimidine ring outside, while the $\mathrm{H} \cdots \mathrm{N}$ spike represents the complementary. The $\mathrm{H} \cdots \mathrm{H}$ interactions, seen as a wide spike on the fingerprint plot are represented by the $\mathrm{C} 13-\mathrm{H} 13 \mathrm{C} \cdots \mathrm{H} 23 \mathrm{~A}-\mathrm{H} 23 \mathrm{C}\left(\mathrm{d}_{\mathrm{i}}+\mathrm{d}_{\mathrm{e}} \sim 2.35 \AA\right.$ ). Compared with ETRDMSO1 structure, the supramolecular synthons have similar geometries, having the strong $\mathrm{N} \cdots \mathrm{H} / \mathrm{H} \cdots \mathrm{N}$ and $\mathrm{H} \cdots \mathrm{O}$ interactions implied in the formation. The fingerprint plot of dimethylacetamide molecule is presenting a similar $\mathrm{O} \cdots \mathrm{H}$ spike as in the two dimethyl sulfoxide solvates, $\mathrm{d}_{\mathrm{i}}+\mathrm{d}_{\mathrm{e}} \sim 2.18 \AA$, with the N4$\mathrm{H} 4 \mathrm{~B}$ primary amide donor outside the surface and the $\mathrm{O} 2$ oxygen acceptor inside; the wider $\mathrm{H} \cdots \mathrm{H}$ spike is resembled by the H23A-H23C $\cdots \mathrm{C} 13-\mathrm{H} 13 \mathrm{C}$ interaction $\left(\mathrm{d}_{\mathrm{i}}+\mathrm{d}_{\mathrm{e}} \sim 2.35 \AA\right)$; the $\mathrm{H} \cdots \mathrm{N}$ interaction having the shortest distance $\mathrm{d}_{\mathrm{i}}+\mathrm{d}_{\mathrm{e}} \sim 2.55 \AA$ for the $\mathrm{C} 21-\mathrm{H} 21 \mathrm{~B} \cdots \mathrm{N} 1$ interaction, where the C21 donor of the acetamide fragment is inside the Hirshfeld surface and the nitrile N1 nitrogen is outside. The C24$\mathrm{H} 24 \mathrm{~A} \cdots \mathrm{Br} 1$ interaction, with the methyl donor of dimethylacetamide molecule inside the surface and the bromide outside is translated in the fingerprint plot as a small bump, which shows a large distance $\mathrm{d}_{\mathrm{i}}+\mathrm{d}_{\mathrm{e}} \sim 3.17 \AA$ A. $\mathrm{N} \cdots \mathrm{H}$ spike is related to $\mathrm{C} 23-\mathrm{H} 23 \mathrm{C} \cdots \mathrm{N} 7$ interaction, which links two neighbouring solvent molecules with the methyl donor outside the Hirshfeld surface and N7 nitrogen acceptor inside surface.

The two independent etravirine molecules in the asymmetric unit of ETR-Dioxane shows different fingerprint plot, which is caused by the different molecular environment. The fingerprint of molecule A shows a very sharp narrow $\mathrm{H} \cdots \mathrm{O}$ spike which is produced by the $\mathrm{N}-\mathrm{H} \cdots \mathrm{O}$ hydrogen bonds where both amides are donors and the dioxane oxygens acceptors having the lowest $\mathrm{d}_{\mathrm{i}}+\mathrm{d}_{\mathrm{e}} \sim 1.92 \AA$ for the N4A-H4 donor inside the surface and the $\mathrm{O} 2$ oxygen acceptor outside the surface. The $\mathrm{H} \cdots \mathrm{N}$ spike (overlapped with the more dominant $\mathrm{H} \cdots \mathrm{O}$ ) has the $\mathrm{d}_{\mathrm{i}}+\mathrm{d}_{\mathrm{e}} \sim 2.19 \AA$ for the N4A-H4AB $\cdots \mathrm{N} 1 \mathrm{~B}$ interaction with the donor of A molecule inside the surface and the nitrile nitrogen N1B acceptor of the B molecule outside. The $\mathrm{H} \cdots \mathrm{H}$ spike (having the shortest distance $\mathrm{d}_{\mathrm{i}}+\mathrm{d}_{\mathrm{e}} \sim 2.20 \AA$ for the C20A-H20E $\cdots \mathrm{C} 13 \mathrm{~B}-$ H13Cinteraction, which links the methyl groups of aryl rings in A and B molecules. The N $\cdots \mathrm{H}$ spike is extended to the shortest distance $\mathrm{d}_{\mathrm{i}}+\mathrm{d}_{\mathrm{e}} \sim 2.20 \AA$, for N4B-H4BB $\cdots \mathrm{N} 1 \mathrm{~A}$ hydrogen bond, which links the primary amide donor of molecule $B$ with the N1A nitrile nitrogen. The $\mathrm{C} \cdots \mathrm{H}$ spike shows the shortest $\mathrm{d}_{\mathrm{i}}+\mathrm{d}_{\mathrm{e}} \sim 2.57 \AA$ for the N4B-H4BA...C15A interaction which links the primary amide of B molecule which is outside the Hirshfeld surface with the C15A carbon of the aryl ring in molecule A. (Fig. 8e) The fingerprint plot of B molecule lacks the $\mathrm{H} \ldots \mathrm{O}$ spike, thus the B molecules are not involved in strong $\mathrm{N}-\mathrm{H} \cdots \mathrm{O}$ hydrogen bonds. The $\mathrm{H} \cdots \mathrm{N}$ spike is seen in mirror $(\mathrm{N} \cdots \mathrm{H})$ compared with the molecule A fingerprit's plot having the donor inside surface and the acceptor outside. Once again, the $\mathrm{H} \cdots \mathrm{H}$ spike resembles the shortest distance $\mathrm{d}_{\mathrm{i}}+\mathrm{d}_{\mathrm{e}} \sim 2.20 \AA$ as in molecule A, being valid for the C13B-H13C ...C20A$\mathrm{H} 20$ E interaction. The N $\cdots \mathrm{H}$ spike has the shortest $\mathrm{d}_{\mathrm{i}}+\mathrm{d}_{\mathrm{e}} \sim 2.19 \AA$ for the N4A-H4AB $\cdots \mathrm{N} 1 \mathrm{~B}$ hydrogen bond between the primary amide donor of molecule A situated outside the surface and the the nitrile nitrogen acceptor of molecule B situated inside the surface, in the case of molecule A being labelled as

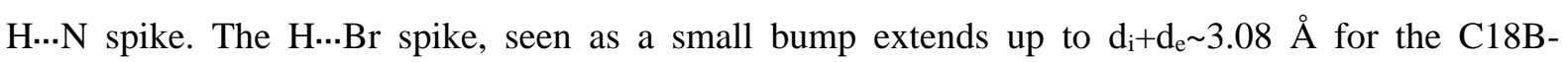


H18B $\cdots$ Br1B interaction, which links two B molecules, the bromide acceptor inside Hirshfeld surface and the acceptor in the aryl ring outside surface. The $\mathrm{Br} \cdots \mathrm{H}$ spike with $\mathrm{d}_{\mathrm{i}}+\mathrm{d}_{\mathrm{e}} \sim 3.05 \AA$ is represented by the $\mathrm{C} 3-\mathrm{H} 3 \mathrm{C} \cdots \mathrm{Br} 1 \mathrm{~B}$ interaction, the donor bromide of molecule $\mathrm{B}$ inside Hirshfeld surface and the acceptor belonging to the $\mathrm{O} 2-\mathrm{O} 3$ dioxane fragment outside surface.

The fingerprint plot of $\mathrm{O} 1$ dioxane molecule is showing a small bump for the $\mathrm{H}$... O interactions, which links the two distinct dioxane molecules via the C1-H1B $\ldots \mathrm{O} 3$ bond at the lowest $\mathrm{d}_{\mathrm{i}}+\mathrm{d}_{\mathrm{e}} \sim 2.56 \AA$, with the donor inside the surface and the ether oxygen acceptor outside. The wide $H \cdots H$ spike $\left(d_{i}+d_{e} \sim 2.33 \AA\right)$ corresponds to the C5-H5A $\cdots \mathrm{H} 1 \mathrm{~B}-\mathrm{C} 1$ interaction and links the two dioxane molecules. The $\mathrm{O} \cdots \mathrm{H}$ spike is complementary with the $\mathrm{H} \cdots \mathrm{O}$ spike in molecule $\mathrm{A}$, with the difference that the secondary amide donor is outside the surface and the ether oxygen acceptor inside $\left(\mathrm{d}_{\mathrm{i}}+\mathrm{d}_{\mathrm{e}} \sim 2.57 \AA\right)$ and is represented by $\mathrm{N} 2 \mathrm{~A}-\mathrm{H} 2 \mathrm{~A} \cdots \mathrm{C} 1$ bond

The small $\mathrm{H} \cdots \mathrm{N}$ spike in the fingerprint plot of O2-O3 dioxane molecule has the $\mathrm{d}_{\mathrm{i}}+\mathrm{d}_{\mathrm{e}} \sim 2.51 \AA$ and is related with the $\mathrm{C} 3-\mathrm{H} 3 \mathrm{D} \ldots \mathrm{N} 6 \mathrm{~A}$ bond, which links the O2-O3 dioxane fragment with the nitrile functional group of A molecule. Considering the $\mathrm{H} \cdots \mathrm{H}$ intercontacts, the fingerprint plot shows a small split: the downside part has the $\mathrm{d}_{\mathrm{i}}+\mathrm{d}_{\mathrm{e}} \sim 2.28 \AA$ for the $\mathrm{C} 3-\mathrm{H} 3 \mathrm{C}$...C4A-H4A interaction linking the dioxane molecule with the phenyl ring of molecule $\mathrm{A}$, where $\mathrm{C} 3-\mathrm{H} 3 \mathrm{C}$ is localized inside the surface and C4A$\mathrm{H} 4 \mathrm{~A}$ outside; the upside part has the $\mathrm{d}_{\mathrm{i}}+\mathrm{d}_{\mathrm{e}} \sim 2.30 \AA$ and represents the $\mathrm{C} 5-\mathrm{H} 5 \mathrm{~A} \cdots \mathrm{H} 2 \mathrm{~A}-\mathrm{N} 2 \mathrm{~A}$ interaction between the secondary amide of molecule A situated outside the Hirshfeld surface and the dioxane inside. The $\mathrm{O} \ldots \mathrm{H}$ spike, identified as the sharpest on the plot extends up to $\mathrm{d}_{\mathrm{i}}+\mathrm{d}_{\mathrm{e}} \sim 1.92 \AA$ and indicates the strong N4A-H4AA $\cdots \mathrm{O} 2$ hydrogen bond, with the $\mathrm{O} 2$ ether acceptor inside the surface and the primary amide donor outside, just the opposite with the $\mathrm{H} \ldots \mathrm{O}$ splike found in molecule A. The C-H... label on the fingerprint plot $\left(\mathrm{d}_{\mathrm{i}}+\mathrm{d}_{\mathrm{e}} \sim 2.77 \AA\right)$ is indicating the C6-H6C $\cdots л$ interaction, with the dioxane molecule inside the surface and the plenyl ring of the molecule A outside.

ETR-Oxalic salt is characterized by strong $\mathrm{N}-\mathrm{H} \ldots \mathrm{O}$ hydrogen bonds, feature which can be concluded from the fingerprint plot spikes (Fig. 8f). The spike denoted by $\mathrm{H} \cdots \mathrm{O}$ is related to the bifurcated $\mathrm{N}-\mathrm{H} \cdots \mathrm{O}$ hydrogen bonds, with the distance di+de $1.74 \AA$ A between the N2-H2 donor situated inside the Hirshfeld surface and the $\mathrm{O} 3$ oxalate acceptor outside the surface; spike $\mathrm{N} \cdots \mathrm{H}$ spike is represented by nitrile $\mathrm{C} \equiv \mathrm{N}$

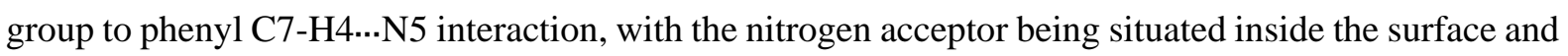
the donor outside ( $\mathrm{di}+\mathrm{de} \sim 2.86 \AA$ ). $\mathrm{H} \cdots \mathrm{H}$ spike is related to primary amide to primary amide $\mathrm{N}-\mathrm{H} \cdots \mathrm{H}-\mathrm{N}$ interaction and has di+de $2.37 \AA$. 


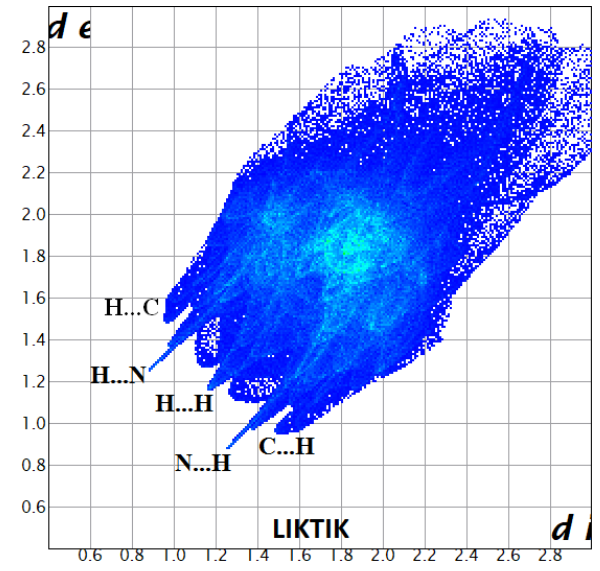

(a)
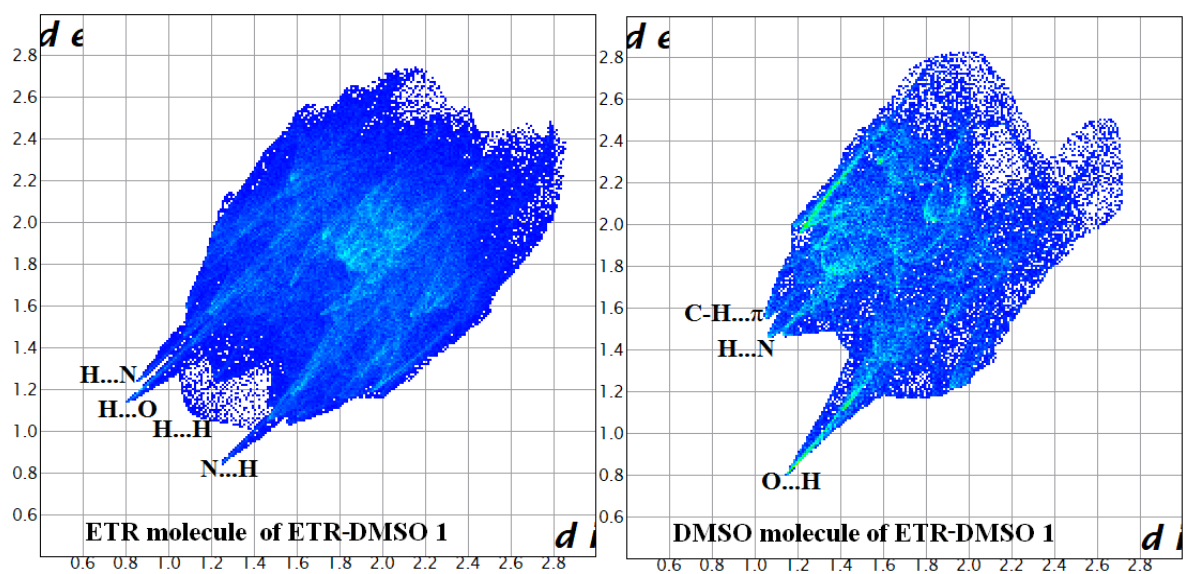

(b)
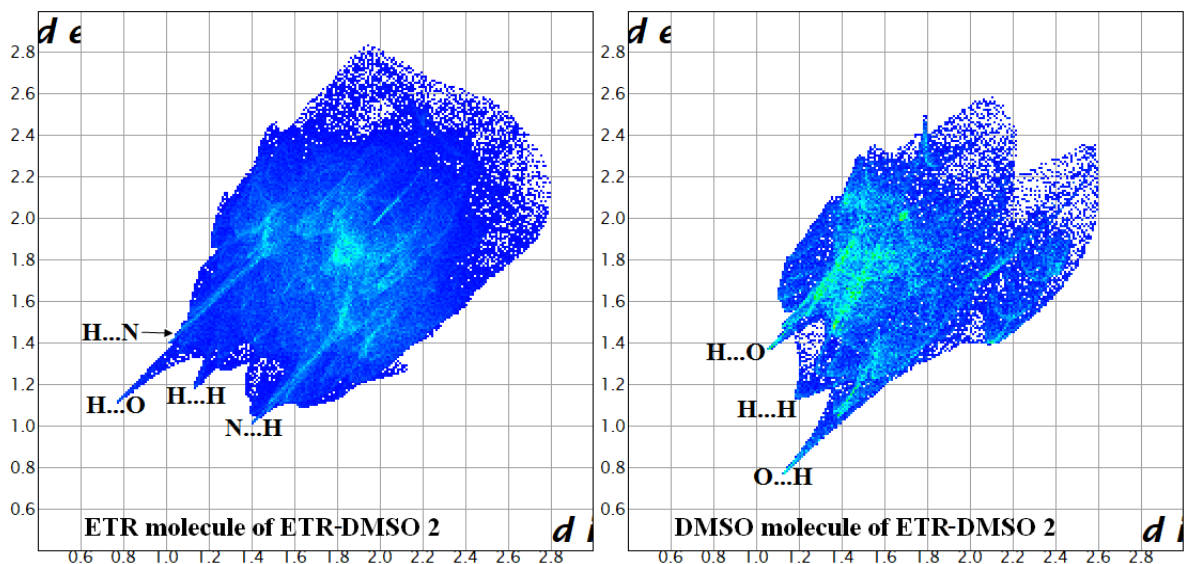

(c) 

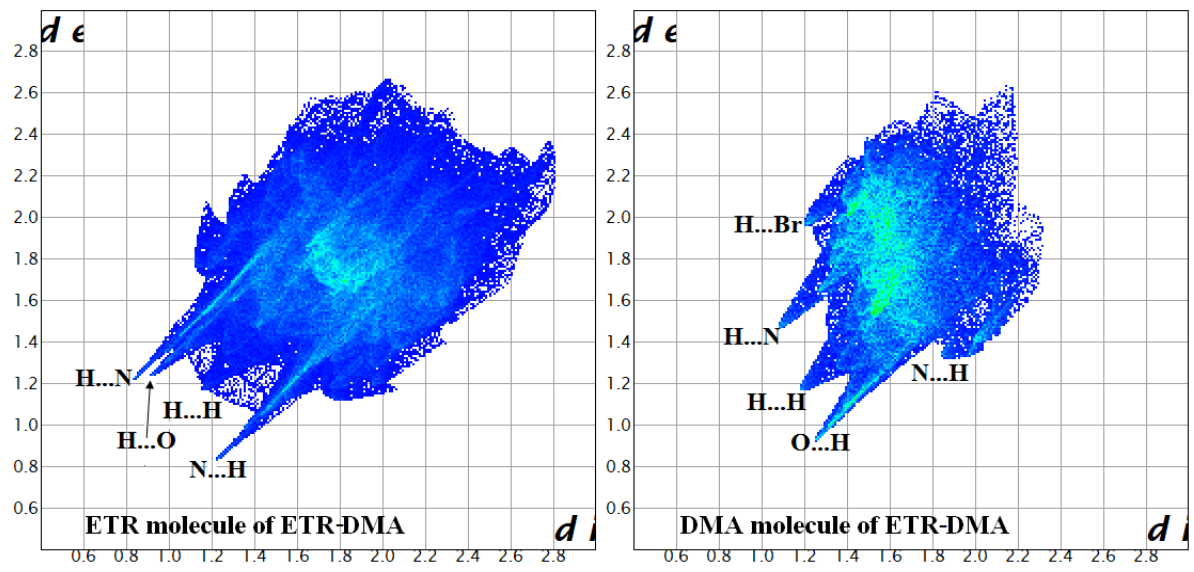

(d)
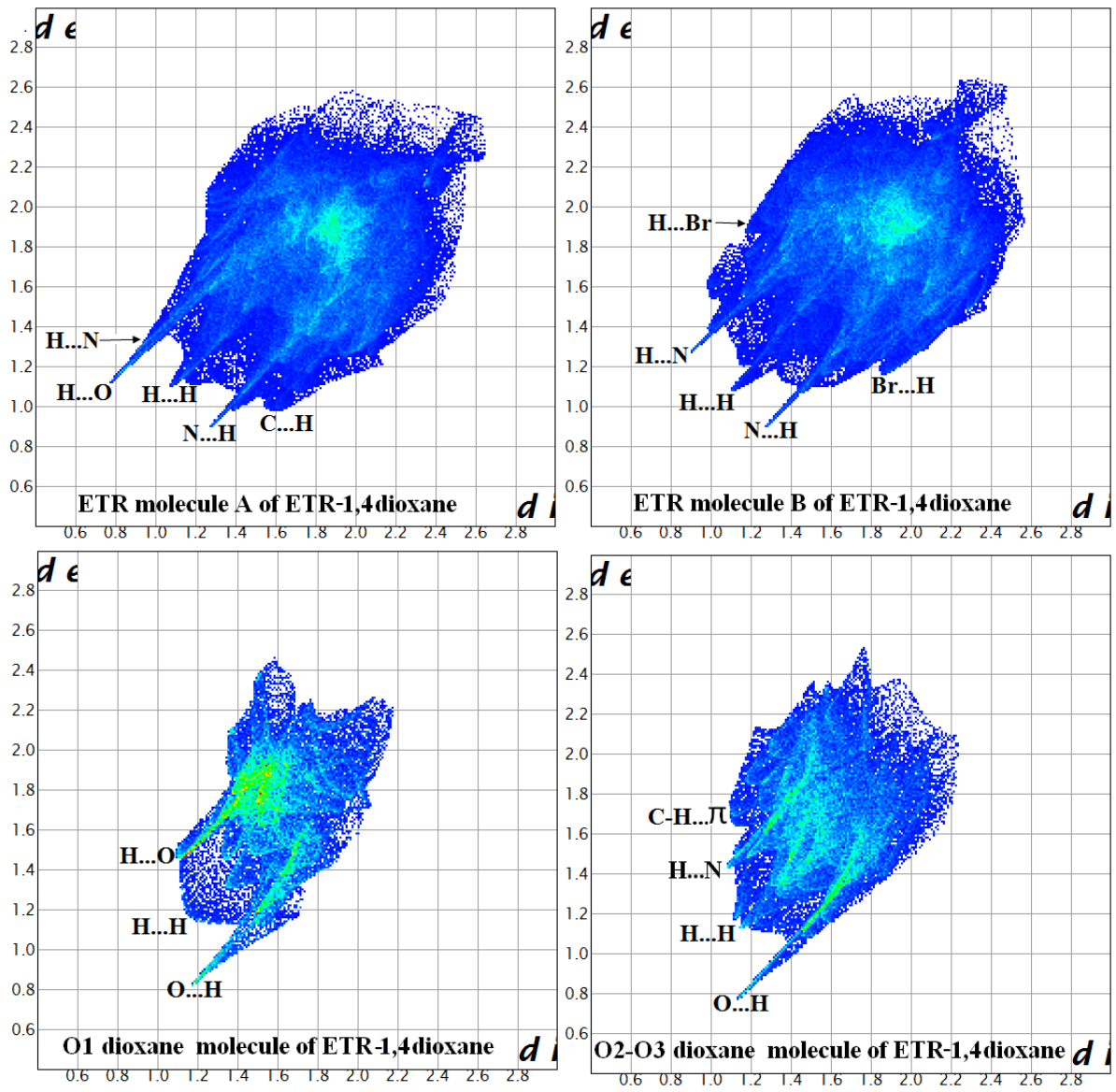

(e) 

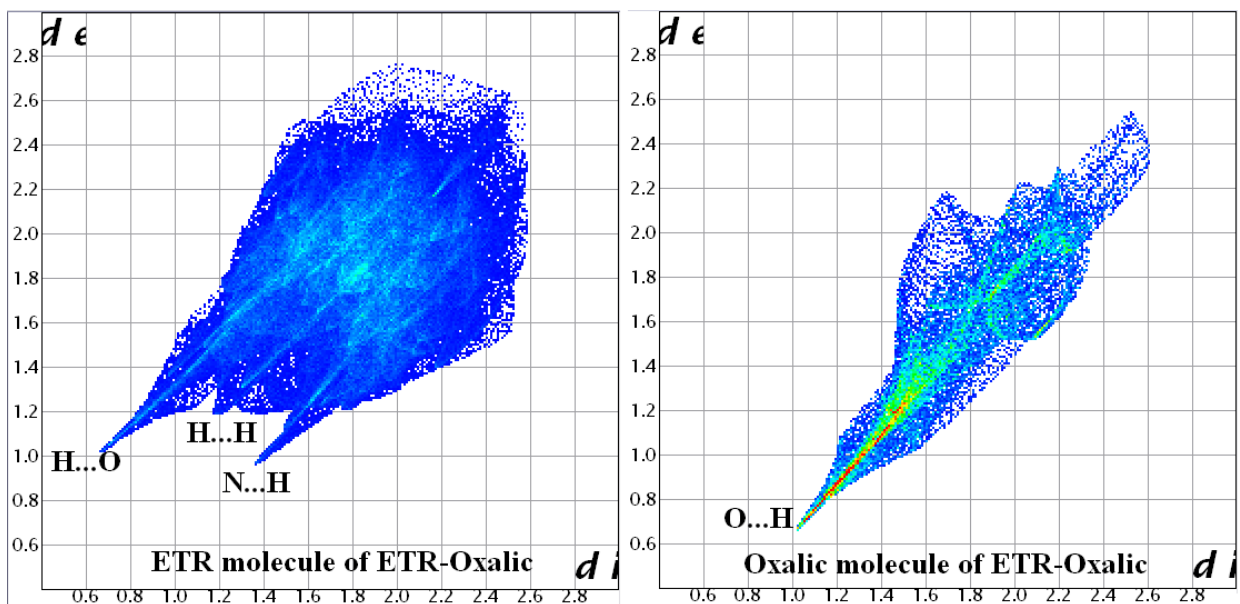

(f)

Figure 8. Fingerprint plots displaying close contacts in studied compounds: Etravirine polymorph (a); ETR-DMSO1 (b); ETR-DMSO2 (c); ETR-DMA (d); ETR-Dioxane (e); ETR-oxalic (f)

Table 3. Breakdown of various contributions to the Hirshfeld surfaces

\begin{tabular}{|c|c|c|c|c|c|c|c|}
\hline Structure & Fragment & $\mathbf{H} \cdots \mathbf{H}$ & $\mathbf{O} \cdots \mathbf{H} / \mathbf{H} \cdots \mathbf{O}$ & $\mathbf{C} \cdots \mathbf{H} / \mathbf{H} \cdots \mathbf{C}$ & $\mathbf{N} \cdots \mathbf{H} / \mathbf{H} \cdots \mathbf{N}$ & $\mathbf{H} \cdots \mathbf{B r} / \mathbf{B r} \cdots \mathbf{H}$ & Others \\
\hline \multirow{2}{*}{ ETR } & ETR & $27.6 \%$ & $2.2 \%$ & $16 \%$ & $27.6 \%$ & $9.5 \%$ & $17.1 \%$ \\
\hline \multirow{2}{*}{ ETR-DMSO1 } & ETR & $29 \%$ & $5.1 \%$ & $21.4 \%$ & $23.2 \%$ & $9.3 \%$ & $12 \%$ \\
\cline { 2 - 8 } & DMSO & $34.3 \%$ & $3.2 \%$ & $14.6 \%$ & $15.5 \%$ & $7.1 \%$ & $25.3 \%$ \\
\hline \multirow{2}{*}{ ETR-DMSO2 } & ETR & $29.7 \%$ & $2.6 \%$ & $18.6 \%$ & $24.8 \%$ & $9.6 \%$ & $14.7 \%$ \\
\cline { 2 - 8 } & DMSO & $47.1 \%$ & $19.8 \%$ & $9.5 \%$ & $10.0 \%$ & $0 \%$ & $13.6 \%$ \\
\hline \multirow{2}{*}{ ETR-DMA } & ETR & $29.0 \%$ & $5.1 \%$ & $21.4 \%$ & $23.2 \%$ & $9.3 \%$ & $12 \%$ \\
\cline { 2 - 8 } & DMA & $34.3 \%$ & $19.1 \%$ & $14.6 \%$ & $15.5 \%$ & $7.1 \%$ & $9.4 \%$ \\
\cline { 2 - 8 } & ETR mol A & $31.4 \%$ & $3.6 \%$ & $15.9 \%$ & $25.8 \%$ & $8.6 \%$ & $14.7 \%$ \\
\cline { 2 - 8 } & ETR mol B & $32 \%$ & $2 \%$ & $13.1 \%$ & $24.4 \%$ & $12.8 \%$ & 15.5 \\
\cline { 2 - 8 } & Dioxane 1 & $56.1 \%$ & $21.9 \%$ & $8.5 \%$ & $9.5 \%$ & $3.9 \%$ & $0.1 \%$ \\
\hline & Dioxane 2 & $60.5 \%$ & $24.8 \%$ & $3.4 \%$ & $11.1 \%$ & $0.1 \%$ & $0 \%$ \\
\hline \multirow{2}{*}{ ETR-Oxalic } & ETR & $28.2 \%$ & $8.4 \%$ & $17 \%$ & $18.1 \%$ & $5.7 \%$ & $22.6 \%$ \\
\hline \multirow{2}{*}{ Oxalic } & - & $84.3 \%$ & $5.9 \%$ & - & - & $9.8 \%$ \\
\hline
\end{tabular}

${ }^{*}$ Dioxane 1 and Dioxane 2 are are the two molecules in the unit cell 
Thermal analysis and stability:
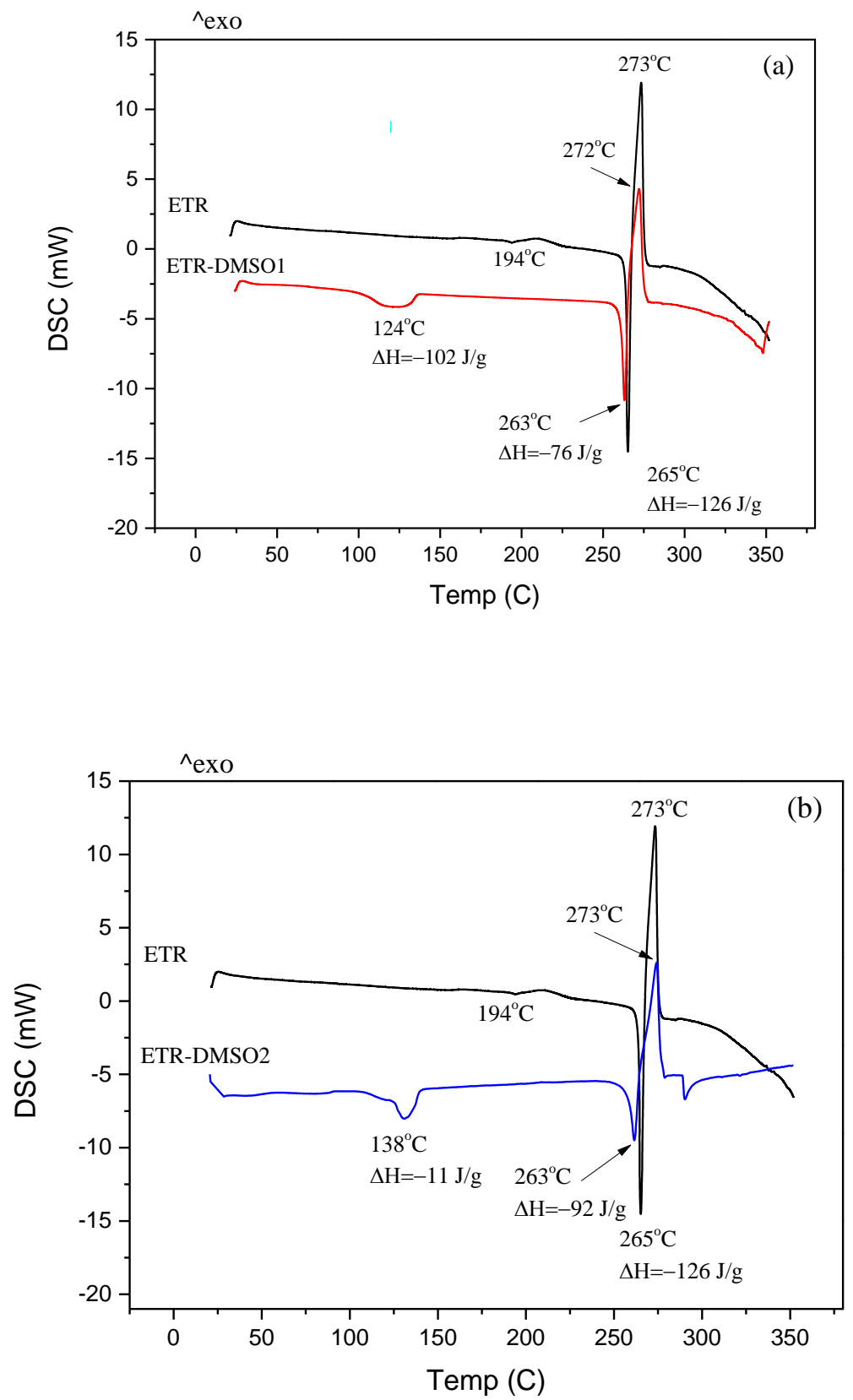

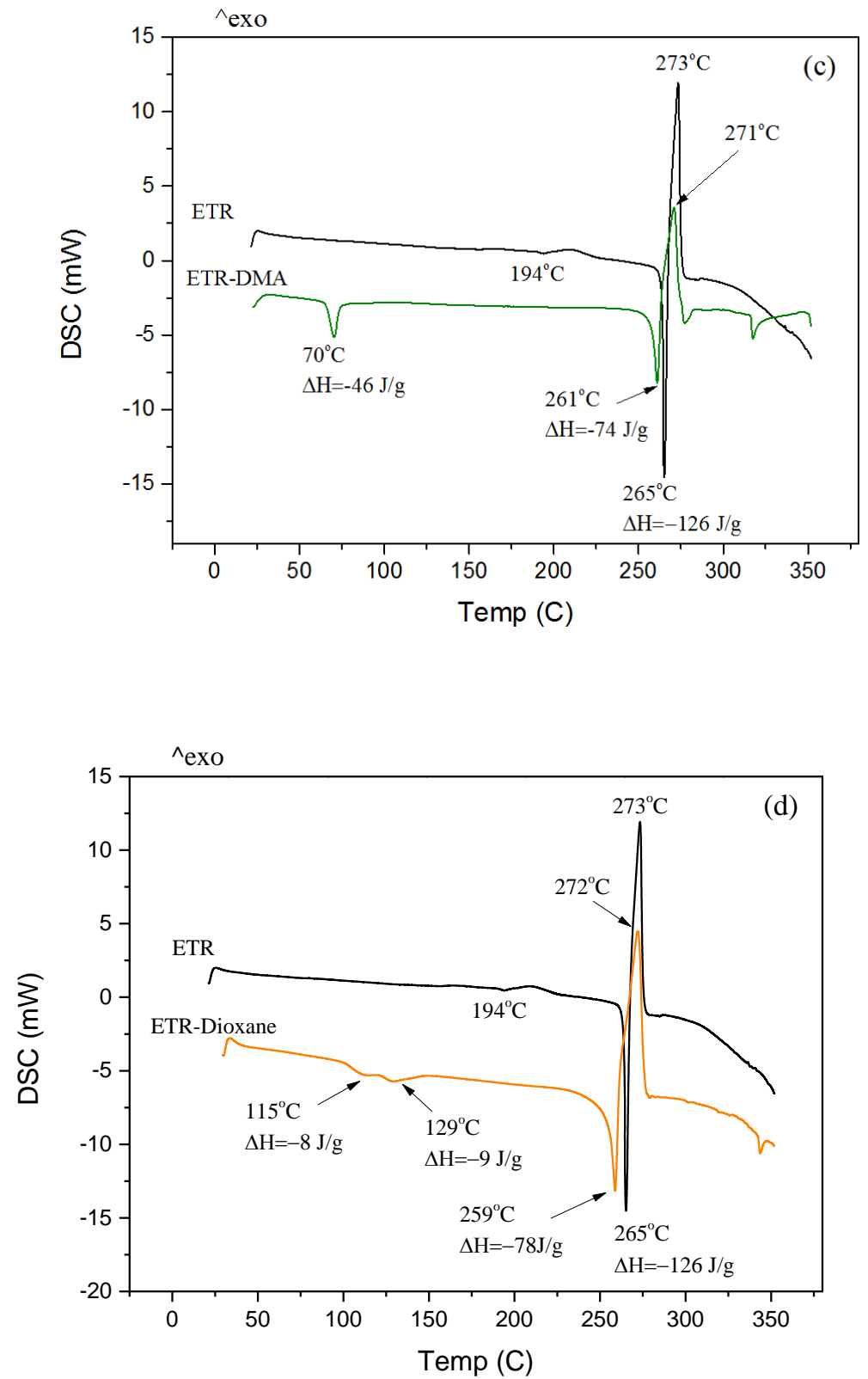


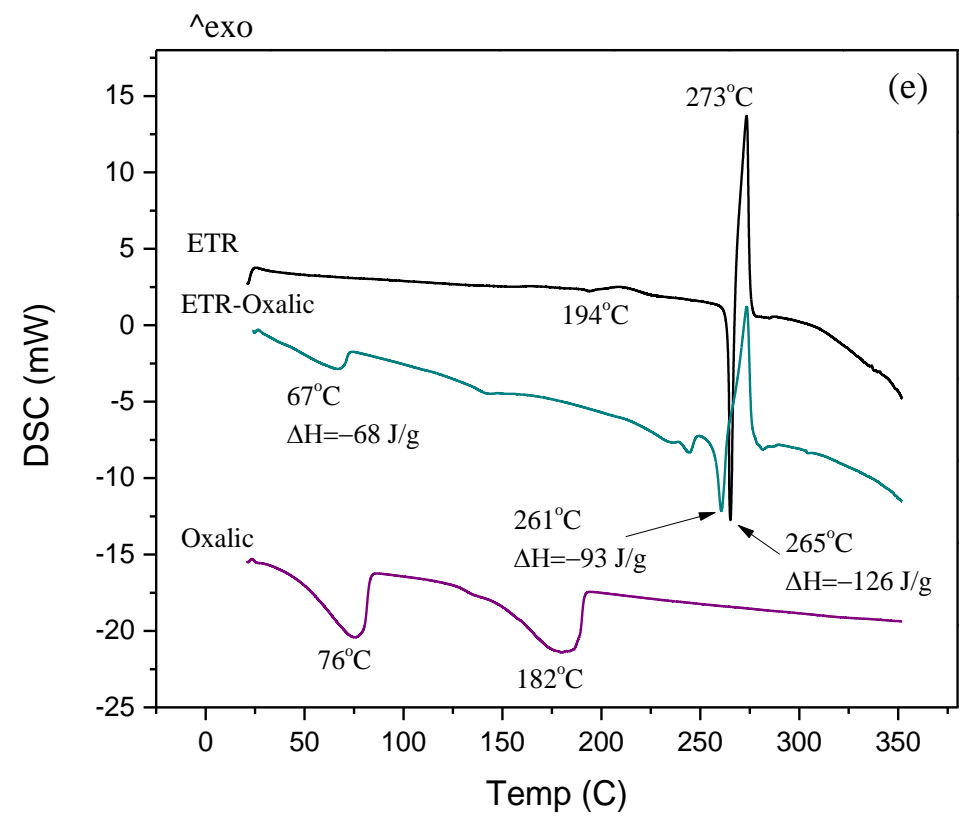

Figure 9. DSC curves of (a, b, c, d) etravirine-solvate and (e) etravirine-oxalate salt

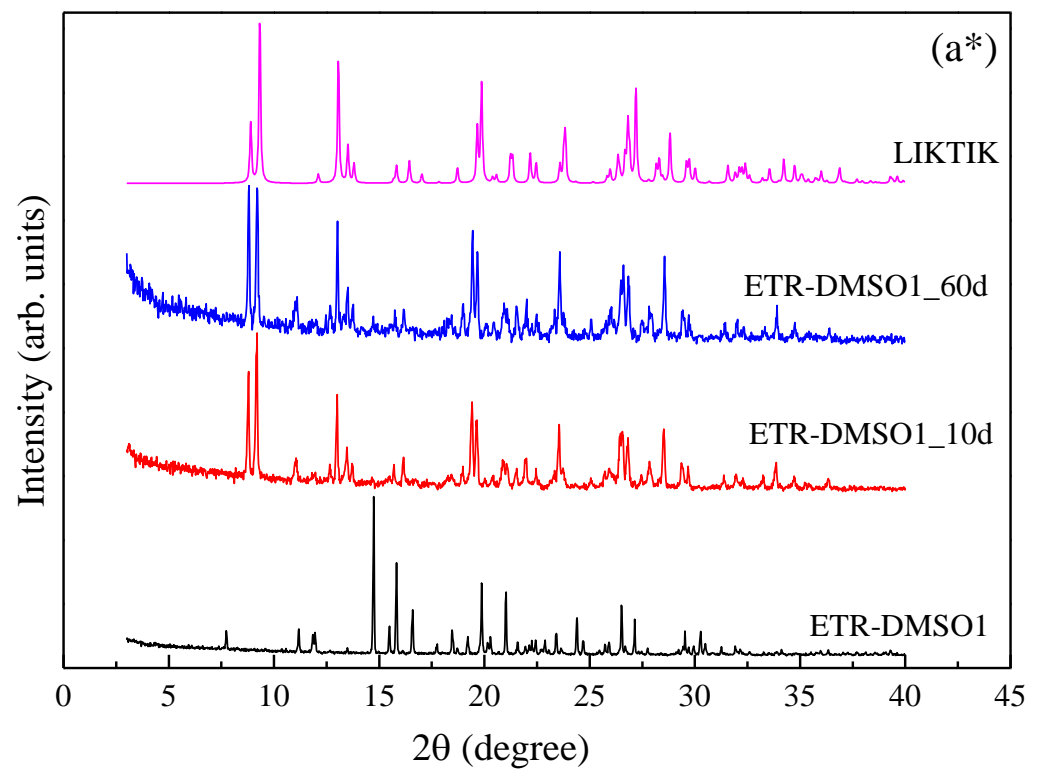



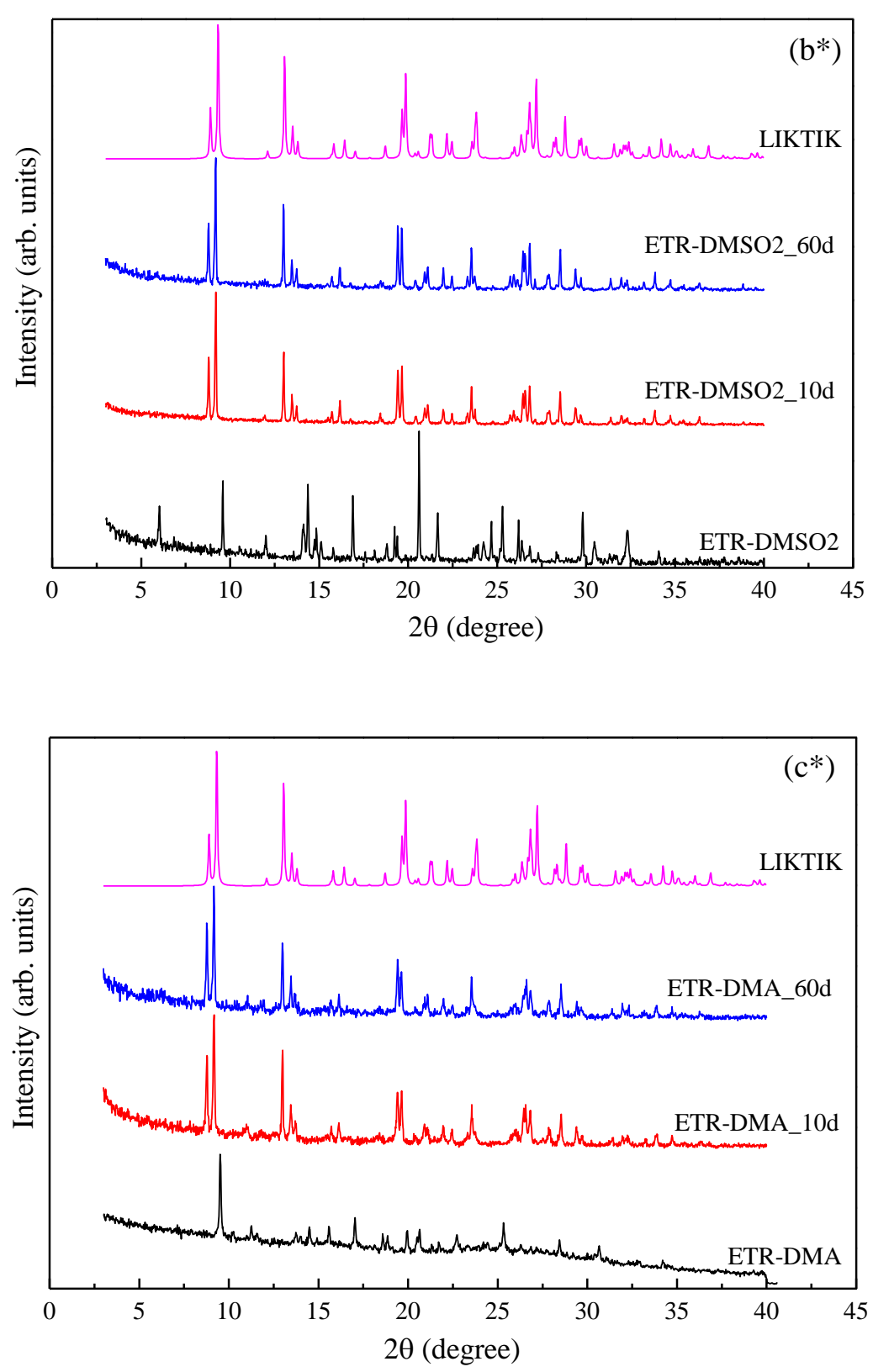

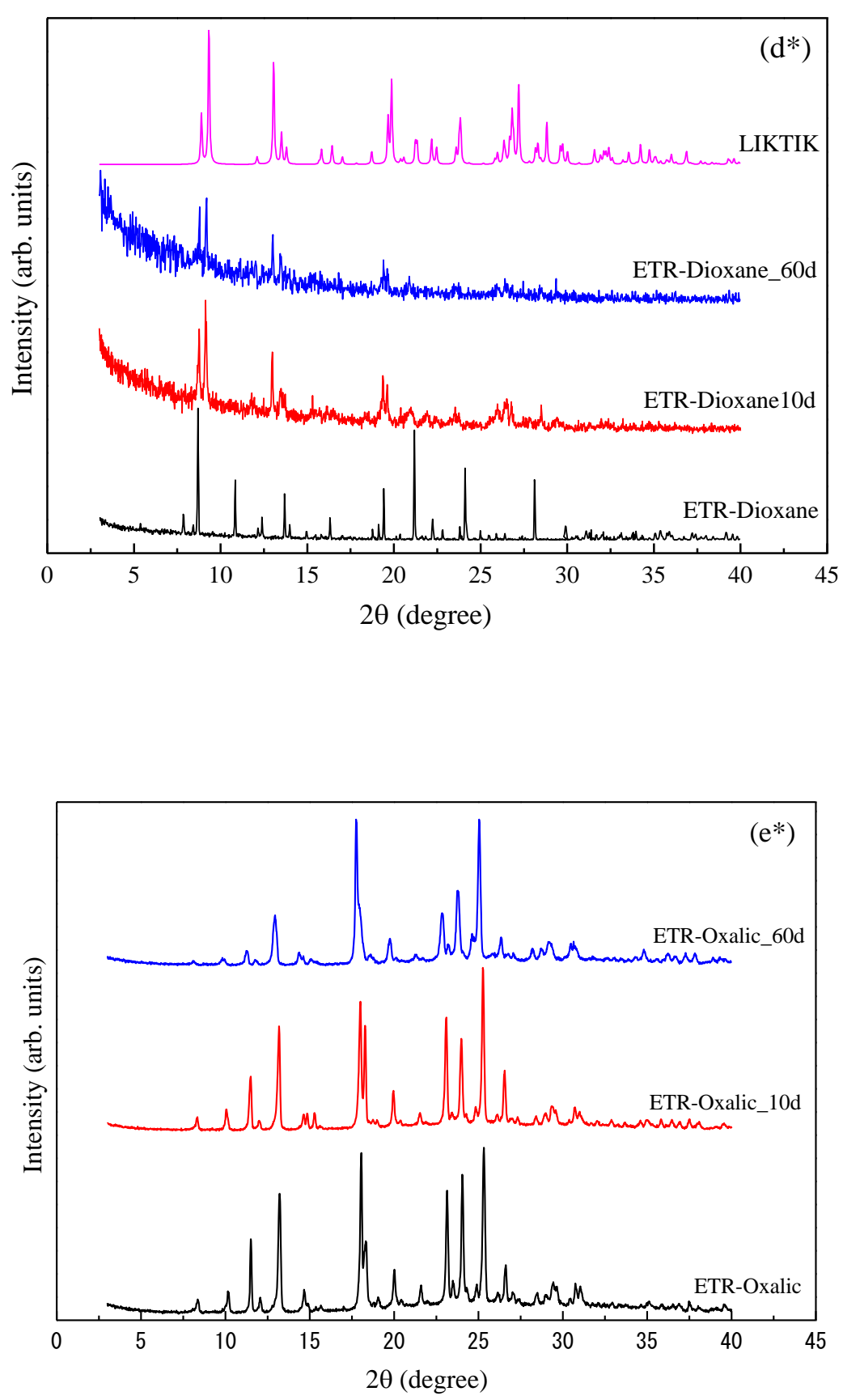

Figure 10 XRPD patterns of $\left(a^{*}, b^{*}, c^{*}, d^{*}\right)$ etravirine-solvate and (e*) etravirine-oxalate salt, after 10 days and 60 days storage at climate chamber.

\section{FTIR analysis:}



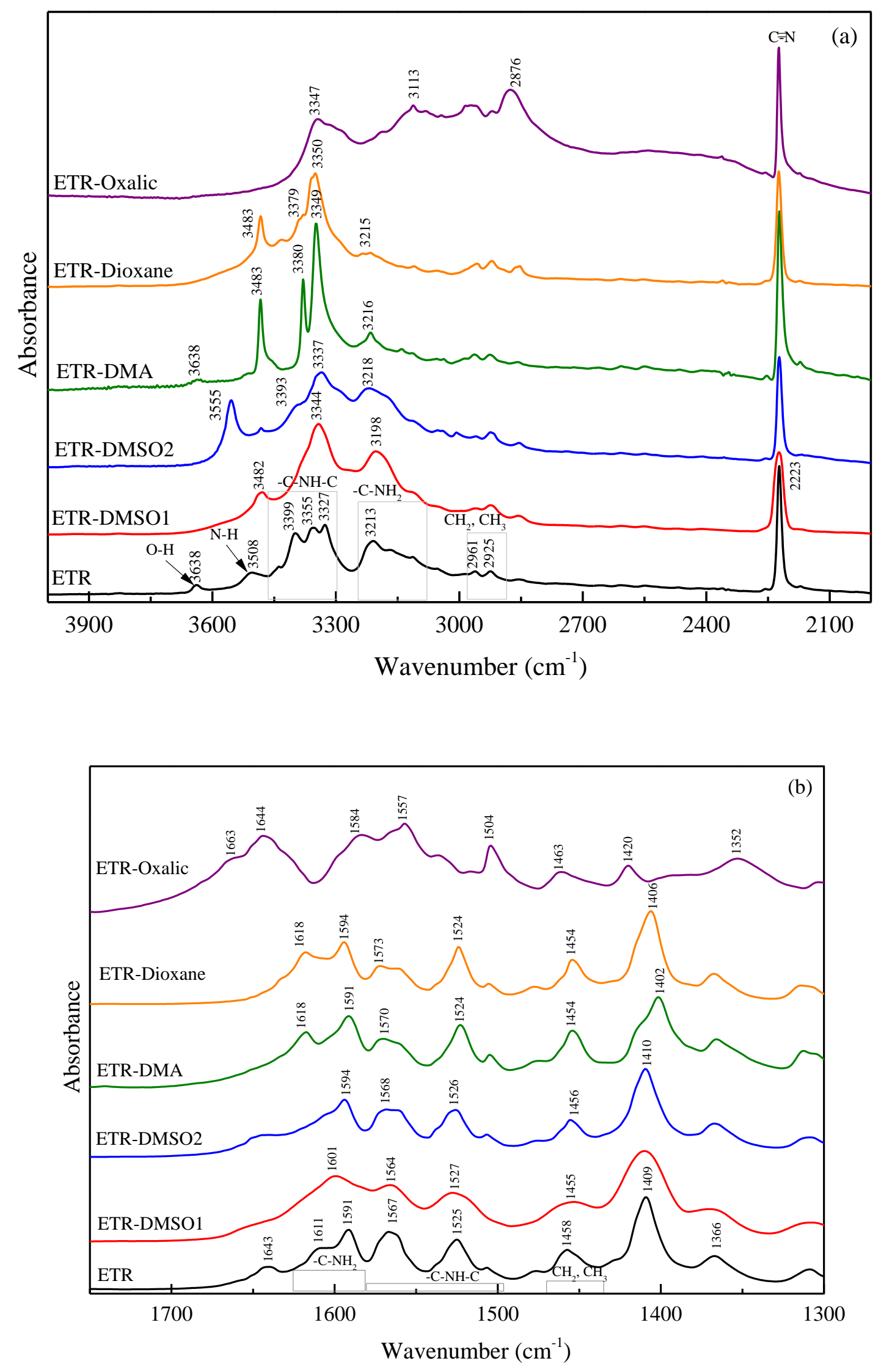

Figure 11 FT-IR spectra for all solvates and salt. 